\title{
EPIDENDRUM TOLIMENSE LINDL. (ORCHIDACEAE), UNA ESPECIE SUDAMERICANA ENCONTRADA EN COSTA RICA
}

\author{
ERIC HÁGSATER \\ Herbario AMO, Apartado Postal 53-123, México, 11320 D.F. México. herbamo@prodigy.net.mx
}

\begin{abstract}
Resumen. Una especie previamente conocida de sur América ha sido encontrada en la Cordillera de Talamanca, Costa Rica. Epidendrum tolimense pertenece al Grupo Elleanthoides y es la primera especie de este grupo que se encuentra fuera de los Andes.

AbstRact. A species previously known from South America is found in the Cordillera de Talamanca, Costa Rica. Epidendrum tolimense belongs to the Elleanthoides Group, and is the first species of this group to be found outside the Andes.
\end{abstract}

Key words / Palabras Clave: Epidendrum tolimense, Epidendrum Grupo Elleanthoides, Orchidaceae, Costa Rica.

La aparición de nuevas especies en lugares aparentemente bien colectados en el pasado no parece tener fin, aun en aquellos países donde la flora orquideológica ha sido bien estudiada. Tal es el caso de esta especie que se ilustra y que fue detectada durante una visita reciente a los herbarios costarricenses aprovechando el simposio sobre conservación de orquídeas que se llevó a cabo en San José en mayo de 2001. Habiendo terminado la contribución sobre el género Epidendrum para el Manual de las Orquídeas de Costa Rica, y dentro de la revisión monográfica del género, no fue difícil detectar que los especímenes en cuestión no corresponden a las especies previamente conocidas de Centro América.

Epidendrum tolimense representa la especie de distribución más norteña del Grupo Elleanthoides, grupo que se distribuye casi exclusivamente en los Andes norteños entre Venezuela y Perú, y que no había sido reportado para Centro América.

Debido al interés de esta especie, se provee una descripción e ilustración (descripción basada en ejemplares de Costa Rica):

Epidendrum tolimense Lindl., Bot. Reg. (1845) misc. 66. 1845

TIPO: ColOMBIA: Tolima, Linden 1272. Holotipo: KL. Ilustración en W-R 5850!

Hierba terrestre y epífita, subcespitosa, ramificada arriba, 20-56 cm de alto. Raíces basales, delgadas, carnosas, $0.5-1 \mathrm{~mm}$ de grosor. Tallos teretes, producidos de cerca de la base del tallo anterior y en ocasiones con raíces a lo largo de la porción basal; ramificados en la parte media apical, los principales hasta $56 \times 0.20-0.30 \mathrm{~cm}$, las ramificaciones muy cortas, 2.5-5.0 × 0.15-0.20 cm. Hojas numerosas, distribuidas a lo largo de casi todo el tallo, las inferiores caedizas; vainas tubulares, estriadas y verrugosas, hasta $2.5 \mathrm{~cm}$ de largo; lámina ovada a lanceolada, ápice agudo, con una quilla dorsal, margen eroso denticulado, 1.6-3.7 x 7-9 $\mathrm{mm}$, las de las ramificaciones generalmente más pequeñas que las de los principales, hasta $2.3 \times 7 \mathrm{~mm}$. Espata ausente. Inflorescencia apical, de los tallos principales y posteriormente, en años siguientes, de las ramificaciones, racemosa, corta, arqueada, nutante; pedúnculo muy corto, terete, de $2 \mathrm{~mm}$ de largo, en ocasiones con una bráctea cerca de la base, elíptica, redondeada, de margen eroso, hasta de $10 \times 2$ $\mathrm{mm}$. Brácteas florales triangulares, acuminadas, hasta $6 \mathrm{~mm}$ de largo. Ovario terete, delgado, liso, no inflado, 7-8 mm de largo. Flores 3, más o menos sucesivas, de color amarillo o verde amarillo, sin datos de fragancia. Sépalos entreabiertos, libres, elípticos, agudos, carnosos, ligeramente cóncavos, 3-nervados, 11 x 2.7-3.7 mm; los laterales ligeramente oblicuos. Pétalos entreabiertos, subparalelos con respecto a la columna, ligeramente arqueados hacia arriba, lineares, agudos, 1-nervados, $9.5 \times 0.6 \mathrm{~mm}$. Labelo unido a la columna, entero, suborbicular al extenderse, apiculado, carnoso, pubescente en la base, abrazando com- 


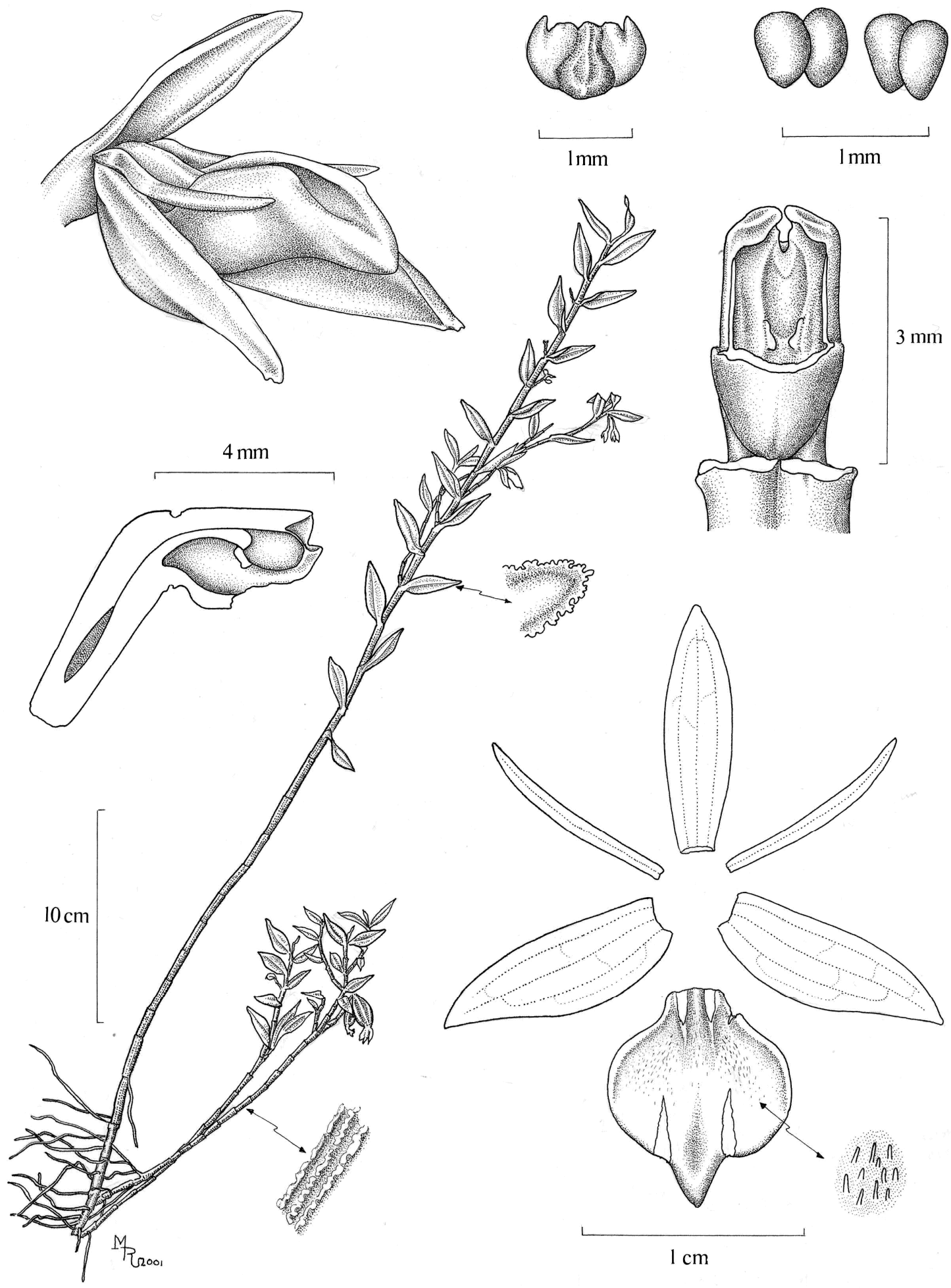

Figura 1. Epidendrum tolimense Lindl. Testigo: R. Aguilar \& O. Garrote 3990 (INB). Dibujo de Marco López Rosas. 
pletamente a la columna en posición natural, $8.6 \times 8.1$ $\mathrm{mm}$; ecalloso. Columna recta, corta, gruesa, arqueada ca. de $90^{\circ}$ con respecto al ovario, $4 \mathrm{~mm}$ de largo. Clinandrio corto, entero. Antera reniforme, diminutamente papilosa, 4-locular. Polinios 4, obovoides. Rostelo apical, hendido. Lóbulos laterales del estigma cortos, cerca de 1/3 del largo de la cavidad estigmática. Nectario poco profundo, sin traspasar el perianto, pubescente frente a la cavidad estigmática, la pubescencia dirigida hacia el fondo del nectario. Cápsula subglobosa, $1.7 \times 1.0 \mathrm{~cm}$, con pedicelo corto y delgado de ca. $1 \mathrm{~mm}$ de largo, sin cuello apical, perianto persistente.

Otros especímenes: Costa Rica: Cartago: Parque Nacional Chirripó: [Puntarenas: Pérez Zeledón, P.I. La Amistad Cordillera de Talamanca] Sendero Herradura-Urán, 3000-3080 m, 8 abril 1995, Reinaldo Aguilar \& O. Garrote 3990, INB! (FIG. 1). [San José: Pérez Zeledón:] P. N. Chirripó, Sendero a Cerro Urán, páramo límite Cartago, 3000-3200 m, B. Gamboa R. et al 1268, INB!

DistribUCIÓN Y ECOLOGÍA: Aparentemente ampliamente distribuida desde Costa Rica (Cordillera de Talamanca) hasta el norte de Ecuador, pasando por Venezuela y Colombia, en páramos a una altitud de 3000-3200 m, epífita y terrestre. Florece en April y May.

RECONOCIMIENTO: Epidendrum tolimense pertenece al Grupo Elleanthoides, Subgrupo Rhombochilum que se caracteriza por el hábito ramificado, pequeñas hojas carnosas y una inflorescencia corta, de 3-4 flo- res, colgante, en un pedúnculo corto y grueso. La especie se reconoce por el tamaño alto de las plantas, flores amarillas o amarillo verdosas con 4 polinios, sépalos de $11 \mathrm{~mm}$ de largo, labelo suborbicular y apiculado con un nectario amplio; es la única especie registrada en Centro América. Se parece a Epidendrum rhodanthum Hágsater \& Dodson que también tiene 4 polinios, y flores algo menores, con sépalos de $8.5 \mathrm{~mm}$ de largo, flores blancas manchadas de rosa viejo y el labelo proporcionalmente más ancho con un nectario angosto. Epidendrum chrysan thum Hágsater \& Dodson es aún más pequeño, de sépalos de $4.5 \mathrm{~mm}$ de largo y únicamente dos polinios. Epidendrum rhombochilum L.O. Wms. tiene sépalos de 7-8 $\mathrm{mm}$ de largo, 2 polinios rajados a un lado. La mayoría de las especies de este grupo se encuentran en Ecuador y las áreas colindantes de Colombia y Perú. El Subgrupo Guacamayense tiene inflorescencias ramificadas con pedúnculos largos, filiformes y hojas angostas.

Estado De COnSERvación: DD. Datos deficientes. Aunque rara, parece tener una distribución amplia y se encuentra en áreas protegidas en los páramos a altitudes elevadas.

Etimología: En referencia a la provincia colombiana de Tolima, en la cual fue colectado el tipo.

\section{REFERENCIAS BIBLIOGRÁFICAS}

Hágsater, E., en prensa. Epidendrum, en Manual de las Orquídeas de Costa Rica, INBIO. 